\title{
Effect of Sr Doping on Structural and Transport Properties of $\mathrm{Bi}_{2} \mathrm{Te}_{3}$
}

\author{
Yurii G. Selivanov*(i), Victor P. Martovitskii, Mikhail I. Bannikov and Aleksandr Y. Kuntsevich *(i)
}

\author{
P.N. Lebedev Physical Institute of the RAS, 119991 Moscow, Russia; martovickijvp@lebedev.ru (V.P.M.); \\ bannikov@lebedev.ru (M.I.B.) \\ * Correspondence: selivanovyg@lebedev.ru (Y.G.S.); alexkun@lebedev.ru (A.Y.K.)
}

check for updates

Citation: Selivanov, Y.G.;

Martovitskii, V.P.; Bannikov, M.I.;

Kuntsevich, A.Y. Effect of Sr Doping on Structural and Transport

Properties of $\mathrm{Bi}_{2} \mathrm{Te}_{3}$. Materials 2021,

14, 7528. https://doi.org/10.3390/

ma14247528

Academic Editor: Gang Cao

Received: 1 November 2021

Accepted: 6 December 2021

Published: 8 December 2021

Publisher's Note: MDPI stays neutral with regard to jurisdictional claims in published maps and institutional affiliations.

Copyright: (c) 2021 by the authors. Licensee MDPI, Basel, Switzerland. This article is an open access article distributed under the terms and conditions of the Creative Commons Attribution (CC BY) license (https:// creativecommons.org/licenses/by/ $4.0 /)$.

\begin{abstract}
Search for doped superconducting topological insulators is of prime importance for new quantum technologies. We report on fabrication of $\mathrm{Sr}_{-}$doped $\mathrm{Bi}_{2} \mathrm{Te}_{3}$ single crystals. We found that Bridgman grown samples have $p$-type conductivity in the low $10^{19} \mathrm{~cm}^{-3}$, high mobility of $4000 \mathrm{~cm}^{2} \mathrm{~V}^{-1} \mathrm{~s}^{-1}$, crystal structure independent on nominal dopant content, and no signs of superconductivity. We also studied molecular beam epitaxy grown $\mathrm{Sr}_{x} \mathrm{Bi}_{2-x} \mathrm{Te}_{3}$ films on lattice matched (1 11 1) $\mathrm{BaF}_{2}$ polar surface. Contrary to the bulk crystals thin films have $n$-type conductivity. Carrier concentration, mobility and $c$-lattice constant demonstrate pronounced dependence on Sr concentration $x$. Variation of the parameters did not lead to superconductivity. We revealed, that transport and structural parameters are governed by $\mathrm{Sr}$ dopants incorporation in randomly inserted Bi bilayers into the parent matrix. Thus, our data shed light on the structural position of dopant in $\mathrm{Bi}_{2} \mathrm{Te}_{3}$ and should be helpful for further design of topological insulator-based superconductors.
\end{abstract}

Keywords: topological insulator; topological superconductivity; doping; thin films; molecular beam epitaxy; single crystals

\section{Introduction}

Bismuth chalcogenides as topological insulators (TI) and narrow gap semiconductors represent a vast playground for novel physics and applications in the fields of thermoectricity [1], spintronics [2], unusual superconductivity [3], photodetectors [4], optical coatings [5] etc. Possible existence of Majorana fermions [6,7] and potential use in faulttolerant quantum computing [8] draw a great interest in topological superconductors (TSC) [9]. Fundamental interest in search for materials that can display topological superconductivity (TS) is also supported by features such as zero bias conduction peak $[10,11]$ and delocalized Andreev bound states [12].

Due to the strong spin-orbit coupling the superconductors derived directly from the topological insulators are promising candidates for TSCs. Binary bismuth-based TIs $\mathrm{Bi}_{2} \mathrm{Se}_{3}$ and $\mathrm{Bi}_{2} \mathrm{Te}_{3}$ both have tetradymite structure and become superconductors under high pressure $[13,14]$ or due to the proximity effect $[15]$ in close contact of TI with conventional superconductor. Still, doping is more straightforward and flexible approach to achieve superconductivity or to modify transport, optical and magnetic properties of parent TI.

A bulk topological superconductivity with critical temperature $T_{c}$ around $3 \mathrm{~K}$ was most intensively studied in the $n$-type doped 3D TIs of the bismuth selenide family $\mathrm{M}_{x} \mathrm{Bi}_{2} \mathrm{Se}_{3}$ (where $\mathrm{M}=\mathrm{Cu}, \mathrm{Sr}$, and $\mathrm{Nb}$ ) [3,10,11,16-22]. Only a few papers reported superconductivity derived from the p-type doped sister compound bismuth telluride $\mathrm{A}_{x} \mathrm{Bi}_{2} \mathrm{Te}_{3}$ (where $\mathrm{A}=\mathrm{Tl}$ or Pd) [23-27]. More intriguingly, combination of two non superconductive materials (one of them bismuth telluride) demonstrates superconductivity in epitaxial $\mathrm{Bi}_{2} \mathrm{Te}_{3}-\mathrm{FeTe}$ heterostructures [28-30]. So, $\mathrm{Bi}_{2} \mathrm{Te}_{3}$ is an attractive platform for creating TSC. Indeed, one may expect to achieve superconductivity with novel appropriate dopant atoms. We could bargain for the hole conductivity by Fermi level tuning if $\mathrm{Sr}^{2+}$ would successfully act as an acceptor replacing $\mathrm{Bi}^{3+}$ in the crystalline matrix. 
In our recent paper [31] we have grown Sr-doped $\mathrm{Bi}_{2} \mathrm{Se}_{3}$ thin films and bulk crystals with a wide range of Sr-content. The films differ from the bulk crystals in their structure, morphology and electrophysical properties. Replacempent of Se for Te may change the structure and properties of the films and bulk crystals in Te-based system. Novel results would also allow to shed light on the different behaviour of Sr dopant atoms in thin films and bulk crystals. Further thin-film technology optimization may open the door for manufacturing superconducting bismuth chalcogenides thin films, not yet achieved.

In this study, we report an attempt to achieve superconductivity in $\mathrm{Sr}$-doped $\mathrm{Bi}_{2} \mathrm{Te}_{3}$ bulk single crystals and epitaxial thin films. Crystals were obtained by modified Bridgman method, and thin films were MBE deposited on $\left(\begin{array}{lll}1 & 1 & 1\end{array}\right) \mathrm{BaF}_{2}$ substrates. We performed detailed structural and low temperature magnetotransport studies. While crystals have $p$-type conductivity, thin films demonstrate $n$-type transport. Structure of the films and the crystals differ drastically as well. In bulk crystals the correlation between $\mathrm{Sr}$ content and clattice parameter was not observed. In the epitaxial layers $c$-lattice parameter systematically grows with nominal Sr content, however this dependence is weaker than in Sr-doped $\mathrm{Bi}_{2} \mathrm{Se}_{3}$ films [31]. We employed grazing diffraction at the $\left(\begin{array}{lll}1 & 0 & 1\end{array}\right)$ reflection and revealed secondary phases containing Bi-Bi bilayers. Both in bulk crystals and thin films the superconductivity was not observed. Our comparative study reveals the different roles of Sr dopant in structure and electronic properties modification for $\mathrm{Bi}_{2} \mathrm{Te}_{3}$ crystals and films. We demonstrate, that transport and structural parameters are governed by Sr dopants incorporation into Bi bilayers between quintuple layers in the parent $\mathrm{Bi}_{2} \mathrm{Te}_{3}$ matrix.

\section{Materials and Methods}

\subsection{Growth and Characterization Techniques}

Single crystals with nominal compositions $\mathrm{Bi}_{2} \mathrm{Te}_{3}, \mathrm{Sr}_{x} \mathrm{Bi}_{2} \mathrm{Te}_{3}, \mathrm{Sr}_{x} \mathrm{Bi}_{2} \mathrm{Te}_{3+x}$ were grown using the modified Bridgman method similarly to Sr-doped $\mathrm{Bi}_{2} \mathrm{Se}_{3}$ [19]. The corresponding molar ratios of the elementary high-purity $\mathrm{Sr}(99,95 \%) \mathrm{Bi}(99,999 \%)$ and $\mathrm{Te}(99,999 \%)$ were placed into quartz ampoule in the inert atmosphere of the glove box, evacuated and hermetically sealed. Material was synthesized by heating the tubes at $850-900{ }^{\circ} \mathrm{C}$ for $24 \mathrm{~h}$ with periodic stirring. Single crystals were grown by a slow cooling of the melt from 750 down to $530{ }^{\circ} \mathrm{C}$ at a rate of $2{ }^{\circ} \mathrm{C}$ per hour. The samples were then annealed at $530{ }^{\circ} \mathrm{C}$ for $24 \mathrm{~h}$ and quenched in cold water. An attempt to fix possible metastable structural phase (as was found for $\mathrm{Cu}$-doped $\mathrm{Bi}_{2} \mathrm{Se}_{3}$ [32]) revealed that samples quenched from slightly higher temperature $\left(560^{\circ} \mathrm{C}\right)$ turned out to be polycrystalline ingots with the crystallites linear dimensions $0.3-1 \mathrm{~mm}$.

Sr-doped $\mathrm{Bi}_{2} \mathrm{Te}_{3}$ films on (111) $\mathrm{BaF}_{2}$ substrates were fabricated in an MBE apparatus EP-1201, (EZAN, Chernogolovka, Russia) with a residual pressure $3 \cdot 10^{-10}$ Torr in the growth chamber [31,33]. Atomic/molecular fluxes were generated from resistive effusion cells loaded with high purity elemental $\mathrm{Te}, \mathrm{Sr}$ and binary $\mathrm{Bi}_{2} \mathrm{Te}_{3}$ compound, and provided growth rate of $\sim 0.3 \mathrm{~nm} / \mathrm{min}$. Fluxes were controlled by measuring beam equivalent pressure (BEP) from each cell. $\mathrm{BEP}$ flux ratio $\mathrm{Te} / \mathrm{Bi}_{2} \mathrm{Te}_{3}$ of $3: 1$ was supported by maintaining stable cell temperatures of 250 and $470{ }^{\circ} \mathrm{C}$ for $\mathrm{Te}$ and $\mathrm{Bi}_{2} \mathrm{Te}_{3}$, respectively. Unlike "ramp up" growth protocol used for $\mathrm{Sr}$-doped $\mathrm{Bi}_{2} \mathrm{Se}_{3}$ films [31], here we followed a single step growth procedure [34] owing to the higher sticking coefficient of Te ad-atoms as compared to the Se flux. The substrate temperature in the present work was kept at $300^{\circ} \mathrm{C}$. Initially, $2 \mathrm{~nm}$ thick $\mathrm{Bi}_{2} \mathrm{Te}_{3}$ buffer layer was deposited, followed by the growth of ternary $\mathrm{Sr}_{x} \mathrm{Bi}_{2-x} \mathrm{Te}_{3}$ film with thickness $26-35 \mathrm{~nm}$. Molar composition $x$ was regulated from 0.003 to 0.283 by increasing the $\mathrm{Sr}$ cell temperature from 266 to $375^{\circ} \mathrm{C}$. Based on measured and approximated fluxes, generated by $\mathrm{Sr}$ and $\mathrm{Bi}_{2} \mathrm{Te}_{3}$ cells, we derived $\mathrm{Sr}$ concentration $x$ in the layers as described in [31]. We used an additional cell with a $\mathrm{BaF}_{2}$ source for deposition of protective $40 \mathrm{~nm}$ thick $\mathrm{BaF}_{2}$ cap layer in the same growth chamber. 


\subsection{X-ray Diffraction}

The X-ray diffraction(XRD) and X-ray reflection(XRR) measurements were carried out on Panalytical MRD Extended diffractometer with a hybrid monochromator (PANalytical, Almelo, The Netherlands), that is a combination of a parabolic mirror and a single crystal $2 \times \mathrm{Ge}(220)$ monochromator. We used triple crystal-analyzer $3 \times \mathrm{Ge}(220)$ to get high resolution $(2 \theta / \omega)$-scanning curves for lattice parameter determinations. Thickness of the films was obtained from (0 0 6) Bragg peak diffraction fringes and/or from X-ray reflection (XRR) spectra.

For measurements of $\mathrm{Sr}$ concentration in single crystals EDX scans were performed using JSM-7001F microscope (JEOL Inc., Tokyo, Japan) with Oxford Instruments analyzer (Oxford Instruments NanoAnalysis \& Asylum Research, High Wycombe, UK).

\subsection{Transport Measurements}

For transport measurements Hall-bar geometries were defined by scratching the films with needle, similarly to Reference [31,33]. The crystals were cut into rectangular shape as explained in Reference [35]. Samples were mounted on the holder and contact wires were attached with silver paint (contact resistance was typically below several hundreds Ohms for films and several tens Ohms for crystals). Low-temperature magnetotransport measurements were performed using a standard lock-in technique at frequencies $13-80 \mathrm{~Hz}$ and measurement current $0.5-1 \mu \mathrm{A}$ (for films and $100 \mu \mathrm{A}$ for crystals) to ensure the absence of overheating at the lowest temperatures. All measurements were performed in the temperature range $1.6 \mathrm{~K}-300 \mathrm{~K}$ using the Cryogenics dry CFMS-16 system (Cryogenic Ltd, London, UK). Perpendicular magnetic field was swept at constant temperatures (typically at $4.2,77$ and $300 \mathrm{~K}$ ) from positive to negative value (typically $2 \mathrm{~T}$ ). In order to compensate contact misalignment, the magnetoresistance (Hall resistance) data were symmetrized (antisymmetrized). Using the $\rho_{x x}(B)$ and $\rho_{x y}(B)$ dependencies we determined the carrier density and Hall mobility.

\section{Results}

\subsection{Single Crystals}

The crystals cleaved easily along the basal plane and demonstrated mirror-like surfaces. Parameters of the studied samples are indicated in the insert of Figure $1 \mathrm{~d}$ and marked by different colors. High-intensity XRD scans with a series of $(003 l)$ peaks (in hexagonal notations) are shown in Figure 1a. and display clear coincidence of the spectra for all the samples. If at low $\mathrm{Sr}$ content (sample 348) we note a complete spectra overlap with that of binary $\mathrm{Bi}_{2} \mathrm{Te}_{3}$, for higher nominal $x$ composition (samples 346,351 ) we register additional reflections shown by three arrows in Figure 1a. So, already at $x=(0.05-0.06)$ the presence of the secondary phase admixture is reliably determined. We ascribe new peaks to formation of $\mathrm{Bi}_{1} \mathrm{Te}_{1}$ phase. An excess metallic $\mathrm{Sr}$ in the $\mathrm{Bi}-\mathrm{Te}$ matrix could displace $\mathrm{Bi}$ atoms and provoke formation of additionally inserted Bi bilayers along with $\mathrm{Bi}_{\mathrm{Te}}$ antisite defects.

Interestingly, for sample 347 with the stoichiometry shifted towards Te excess (Te mole fraction of 3.06) the above three peaks become undetectable. Bearing in mind possible formation of cubic SrTe-related compound, we performed more detailed XRD study of the sample 347 (shown in Appendix A), and did observe another set of weak peaks, corresponding to the defective cubic phase with lattice constant $6.33 \AA$, virtually for $\mathrm{Sr}_{1-x} \mathrm{Bi}_{x} \mathrm{Te}$ compound. Despite the presence of the secondary phases, perfect crystallinity of the crystal body allowed a precise determination of the lattice parameters. Rather small deviations in the angular positions of the $(0015)$ reflection (see insert Figure 1a) for different $x$ values demonstrate that $c$-lattice parameter is not governed by the nominal Sr composition. We note, that prolonged annealing (72 instead of a regular $24 \mathrm{~h}$ ) of the sample 351 resulted in broader $\left(\begin{array}{l}0 \\ 0\end{array}\right.$ 15) reflection (see insert Figure 1a) and the highest $p$-type carrier density (see Figure 1b) due to the increased concentration of the antisite defects. In-plane lattice constant was determined from asymmetric (205) reflections and demonstrated even more significant scatter in obtained values (see Appendix A). 
Fluctuations of the $c$ - and $a$-lattice parameters could be explained by presence of a rather small dopant concentration in the matrix and nonuniform distribution of $\mathrm{Sr}$ atoms in the basal plane of the crystal. Moreover, we revealed a significant bending of the crystalline planes, implying that $\mathrm{Sr}$ atoms may be responsible for suppressing layered growth during crystallization, similar to vicinal growth observed for Sr-doped $\mathrm{Bi}_{2} \mathrm{Se}_{3}$ bulk crystals [36]. Contrary to the $\mathrm{Sr}_{x} \mathrm{Bi}_{2} \mathrm{Se}_{3}[17,31]$, no correlation between $\mathrm{Sr}$ content and lattice parameters was revealed. Thus, $\mathrm{Sr}$ atoms in the Bi-Te system do not enter crystalline structure above some limited $x$ (well below 0.01) value during the melt growth and promote admixture of the secondary phases.
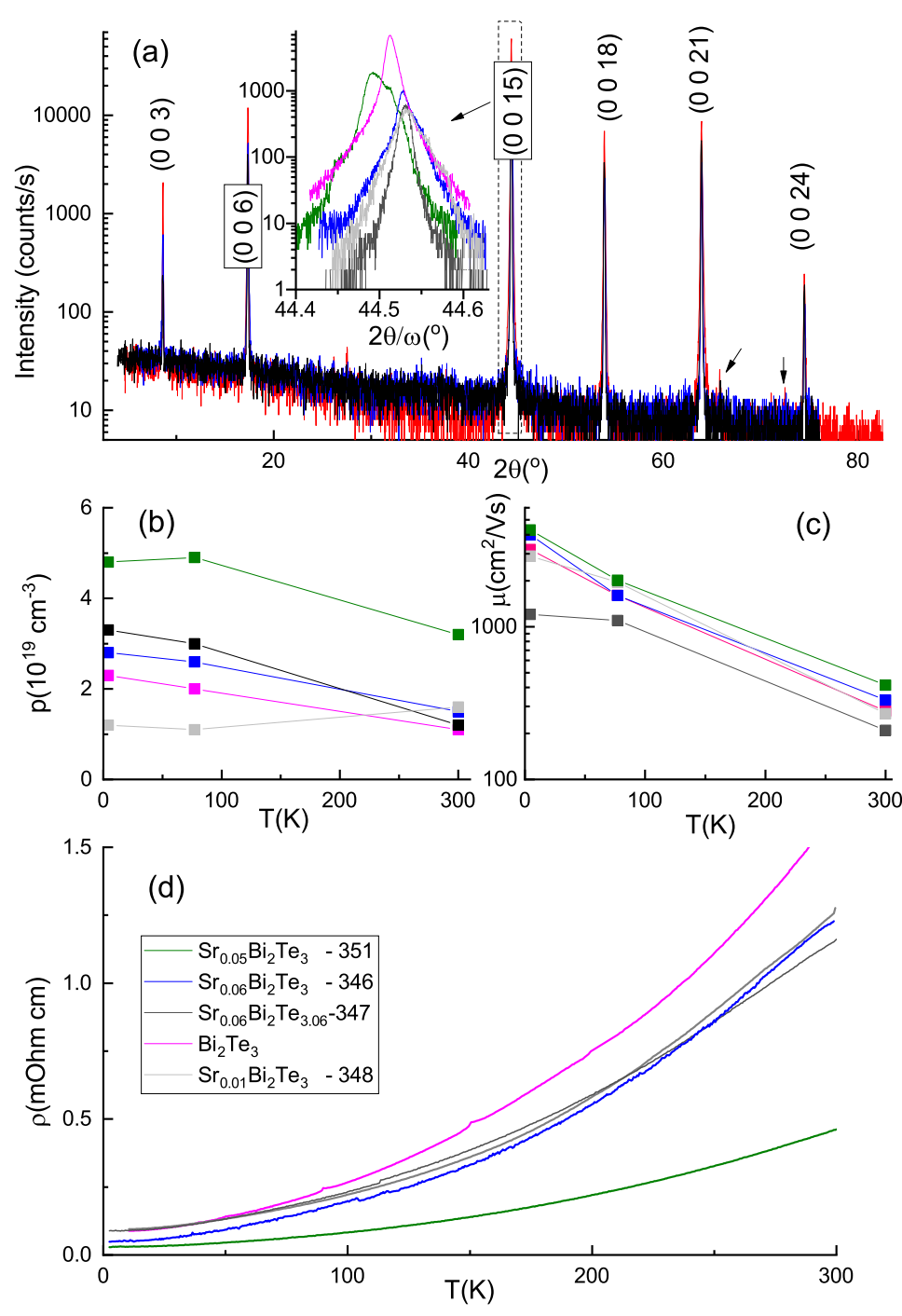

Figure 1. (a) $2 \theta$ XRD scans of the studied crystals. Insert of panel (a) shows $2 \theta / \omega$ scans for precise determination of the $c$-lattice parameter; temperature dependencies of Hall-effect density (b), mobility (c) and resistivity (d).

Transport parameters do not show correlation with $x$ as well. So, despite obtaining in telluride system tempting p-type conductivity, the superconductivity was not observed in bulk $\mathrm{Sr}_{x} \mathrm{Bi}_{2} \mathrm{Te}_{3}$ crystals.

\subsection{Structural Results on Thin Films}

Representative set of the $2 \theta$-scans for thin films with different $\operatorname{Sr}$ content $\left(x_{\mathrm{Sr}}\right.$ is listed in Table 1) is shown in Figure 2a. Intense (111) and (222) reflections from the $\mathrm{BaF}_{2}$ substrate 
are marked by gray vertical bars. Regular $(003 l)$ reflections from the films give evidence for the growth of crystallographically ordered and highly oriented layers with the (001) plane parallel to the (111) cleavage plane of the $\mathrm{BaF}_{2}$ substrate. With the increase of $\mathrm{Sr}$ concentration $x$ from 0 to $\sim 0.2$ the $(003 l)$ peak positions shifted to the lower values (with relative magnitude increase less than $0.3 \%$ ), and the peaks get wider less than a factor of 3. Observed modest spectra modifications reflect survival of high crystallinity along with insignificant structural disorder (see variations in $c_{(0015)}$ and $\Delta \omega_{(0015)}$ in Table 1). While for sample with the highest Sr content $(x=0.283)$ changes are more pronounced, still no additional peaks and no indication of the secondary phases were detected.

Interestingly, for all $\mathrm{Sr}$ doping levels we observe intensity fringes near the central (006) peak (see Figure 2b). Even two split peaks shown in the insert of Figure 3a, both produce well defined Bragg satellite resonances (not shown here) and each correspond nearly to the same film thickness. This observation also indicates that morphology and crystallinity of the films do not degrade significantly with $x$, contrary to $\mathrm{Sr}$-doped $\mathrm{Bi}_{2} \mathrm{Se}_{3}$ films [31]. The period of the fringes might be used for measuring the film thickness [37], $L=\frac{\lambda}{2 \times\left(\sin \omega_{2}-\sin \omega_{1}\right)}$, where $\omega_{1}$ and $\omega_{2}$ are the positions of the satellite maxima, and $\lambda$ is the $\mathrm{X}$-ray wavelength (in our case $1.5406 \AA$ ). These values for the studied films are listed in the " $\mathrm{d}$ " column of Table 1, and are in good agreement with the thickness obtained with XRR data.
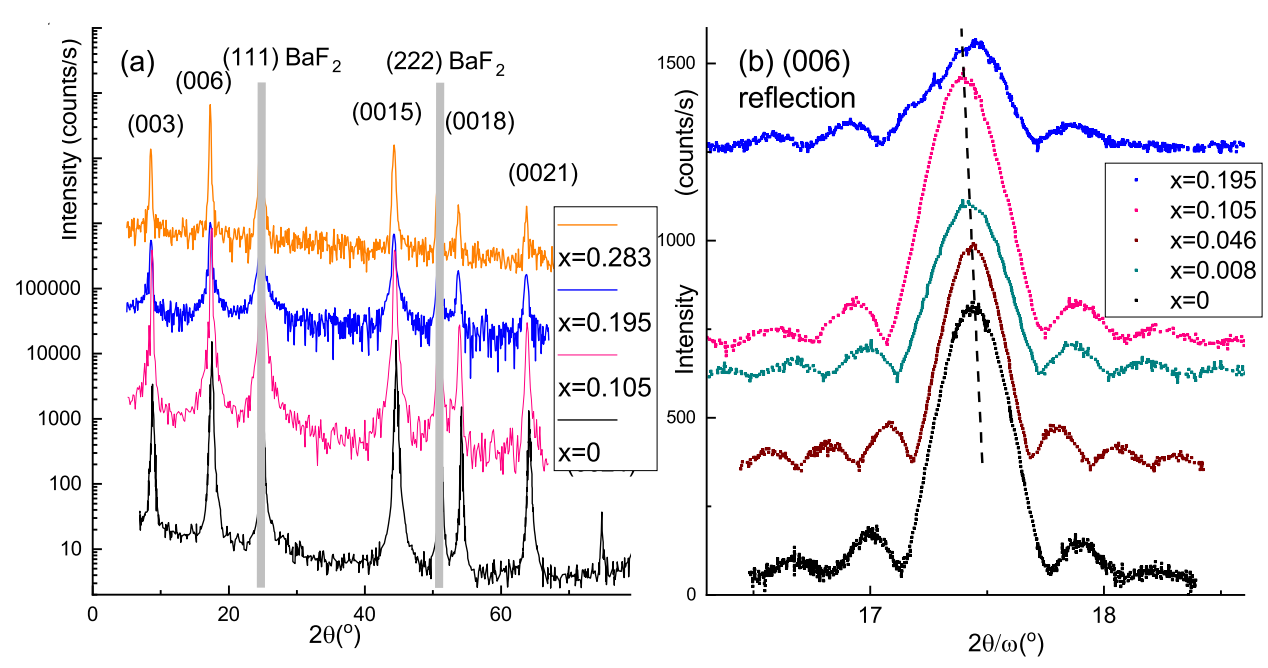

Figure 2. XRD scans for the epitaxial films with different Sr content $x$, indicated in the panel. (a) $2 \theta$ scans. (b) $2 \theta / \omega$ XRD scans on (006) reflection for films with different $x$ content increasing from bottom to top, indicated in the panel. The scan curves are shifted vertically for clarity.

Figure 3 compares structural data for Sr-doped $\mathrm{Bi}_{2} \mathrm{Te}_{3}$ and $\mathrm{Bi}_{2} \mathrm{Se}_{3}$ thin films. Figure $3 \mathrm{a}$ shows the doping level dependencies of the normalized $c / c_{0}$ - and $a / a_{0}$-lattice parameters, where $\left(c_{0}, a_{0}\right)$ are binary $\mathrm{Bi}_{2} \mathrm{Ch}_{3}$ lattice constants, determined from (0015) and (205) reflections, respectively. Data for selenide system are taken from Reference [31]. In the composition range between $x=0$ and $\sim 0.2$ for Sr-doped $\mathrm{Bi}_{2} \mathrm{Te}_{3} c$-lattice parameter is linear and weakly dependent on $x$. The rate of $c$-lattice constant as a function of $x$ in selenides is nearly a factor of 4 faster than in telluride system, pointing that $\mathrm{Sr}$ location sites in two sister compounds are rather different. Anion radius of $\mathrm{Te}^{2-}$ in octahedral surrounding $(2.21 \AA)$ is larger than that for $\mathrm{Se}^{2-}(1.98 \AA)$, and observed slope for tellurides may reflect two scenarios: larger $\mathrm{Sr}^{2+}$ cation $\left(1.18 \AA\right.$ ) replaces $\mathrm{Bi}^{3+}$ cation $(1.03 \AA)$ in the $\mathrm{Bi}_{2} \mathrm{Te}_{3}$ structure and arranges ordered intercalated atoms in the van der Waals gap. With higher Sr content, for film 798, the rocking curve recorded at (0 0 15) reflection turned out to be split (see insert of Figure 3a), revealing the admixture of the second phase. We conclude, that observed phase separation at $x \sim 0.28$ corresponds to the solubility limit of the $\mathrm{Sr}$ dopant in $\mathrm{Bi}_{2} \mathrm{Te}_{3}$ matrix under described $\mathrm{MBE}$ growth conditions. In plane $a$ 
lattice constant for $\mathrm{Sr}$-doped $\mathrm{Bi}_{2} \mathrm{Te}_{3}$ films (Figure $3 \mathrm{~b}$ ) is insensetive to the composition variation in contrast to the selenide system. These observations imply that in telluride matrix incoporation of Sr dopant atoms facilitate formation of specific atomic arrangement in the lattice (see Discussion section) in addition to producing substitutional point defects.

Another notable distinction between Sr-doped $\mathrm{Bi}_{2} \mathrm{Te}_{3}$ and $\mathrm{Bi}_{2} \mathrm{Se}_{3}$ thin films on (111) $\mathrm{BaF}_{2}$ substrate is significant difference in the domain structure. Indeed, telluride $\phi$-scans, shown in Figure 4, display purely single domain film structure (periodic $60^{\circ}$ peaks are not observed) in the whole range of the studied Sr concentrations up to $x \sim 0.28$. While phase separation takes place at comparable doping levels in telluride $(x \sim 0.28)$ and selenide $(x \sim 0.26)$ systems, $\mathrm{Sr}_{x} \mathrm{Bi}_{2-x} \mathrm{Se}_{3}$ films get completely twinned (see. Figure 6 of Reference [31]) already at $x=0.018$. Moreover, in selenide sample with maximal Sr content $60^{\circ}$ twins are accompanied with $30^{\circ}$ rotational domains. Twin domains strongly affect properties of the $\mathrm{Bi}_{2} \mathrm{Ch}_{3}$ family. Recently we demonstrated twin-free MBE growth for binary $\mathrm{Bi}_{2} \mathrm{Te}_{3}$ films on perfectly lattice matched (111) $\mathrm{BaF}_{2}$ substrates [38]. It turned out now that suggested approach preserves non twinned structure even for heavily Sr-doped crystals. We believe, that it is stability of in-plane lattice constant for the whole range of Sr concentration (Figure $3 b$ ), that allows to preserve single domain growth.

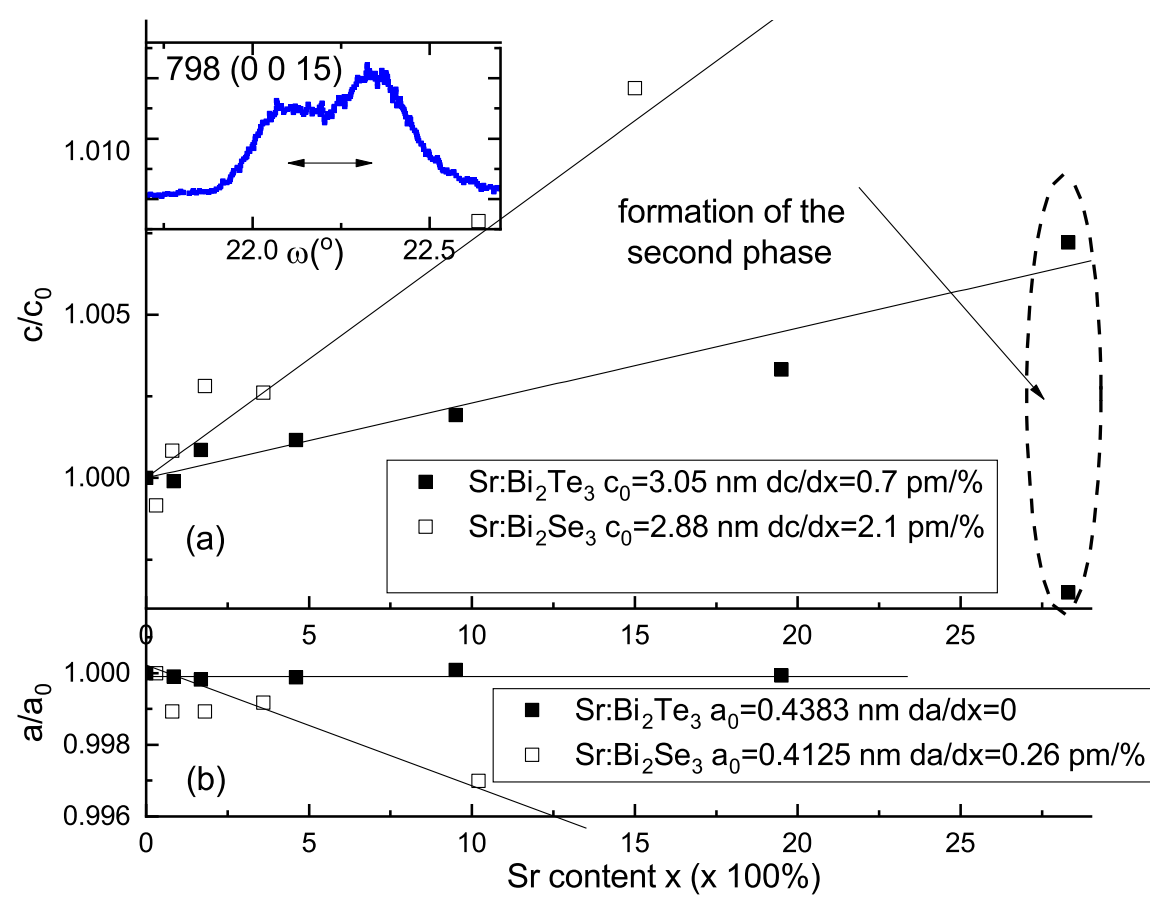

Figure 3. (a) Summary of the $c$-axis lattice parameter value measured on (0015) XRD reflection as a function of $x$ for $\sim 25 \mathrm{~nm}$ thick $\mathrm{Sr}$-doped $\mathrm{Bi}_{2} \mathrm{Te}_{3}$ films (black filled symbols). For comparison we show the data for $\mathrm{Sr}$-doped $\mathrm{Bi}_{2} \mathrm{Se}_{3}$ by empty symbols [31]. Straight lines show approximations of $c(x)$ dependencies for telluride and selenide-based thin films with the slopes $\approx 0.8 \mathrm{pm} / \%$ and $\approx 2.05 \mathrm{pm} / \%$, respectively, (points, corresponding to second phase formation are not used for approximation). The insert shows XRD indication of nonuniformity (rocking curve at (0015)-reflection) of the film with the largest $x$-value. (b) Summary of the $a$-axis lattice parameter value for the same samples with the similar linear fits. 
Table 1. Summary of sample parameters. The amount of $\mathrm{Sr}$ in $\mathrm{Bi}_{2} \mathrm{Te}_{3}$ films $\mathrm{x}_{S r}$ was calculated from the flux ratios. Thickness $d$ and parameters $a, c$ were determined from XRD. Carrier density $(n)$ and mobility $(\mu)$ were obtained from low-field and lowest temperature Hall measurements. Residual-resistivity ratio (RRR) was calculated as room temperature resistivity $\left(R_{T=300 K}\right)$ ratio to the low temperature resistivity minimum.

\begin{tabular}{cccccccccc}
\hline Sample & $\boldsymbol{x}$ & $\mathbf{d} \mathbf{( n m})$ & $\boldsymbol{c}_{(\mathbf{0 0 6})}(\AA)$ & $\boldsymbol{c}_{(\mathbf{0 0 1 5})}(\AA)$ & $\boldsymbol{a}(\mathbf{\AA})$ & $\triangle \boldsymbol{\omega}_{(\mathbf{0 0 1 5})}$ & $\mathbf{R R R}$ & $\mathbf{n}\left(\mathbf{c m}^{-3}\right)$ & $\boldsymbol{\mu}\left(\mathbf{c m}^{\mathbf{2}} / \mathbf{V s}\right)$ \\
\hline $773 \mathrm{~A}$ & 0 & 27.8 & 30.4839 & 30.5053 & 4.3835 & 0.088 & 3 & $1.3 \times 10^{19}$ & 1020 \\
774 & 0.0084 & 34.7 & 30.4890 & 30.5020 & 4.3831 & - & 2.14 & $6.3 \times 10^{18}$ & 428 \\
799 & 0.0168 & 31 & - & 30.5313 & 4.3827 & 0.189 & 1.97 & $1.33 \times 10^{19}$ & 447 \\
$786 \mathrm{~A}$ & 0.046 & 28 & 30.5270 & 30.5404 & 4.3830 & 0.180 & 2.2 & $3.86 \times 10^{19}$ & 213 \\
$787 \mathrm{~A}$ & 0.105 & 26 & 30.5534 & 30.5640 & 4.3839 & 0.209 & 1.828 & $6 \times 10^{19}$ & 206 \\
$794 \mathrm{~A}$ & 0.195 & 27 & - & 30.6065 & 4.3832 & 0.253 & 1.4 & $8.9 \times 10^{19}$ & 80 \\
$798 \mathrm{~A}$ & 0.283 & 29 & - & 30.592 & 4.3866 & 2 peaks & 1.1 & $3 \times 10^{20}$ & 13 \\
\hline
\end{tabular}

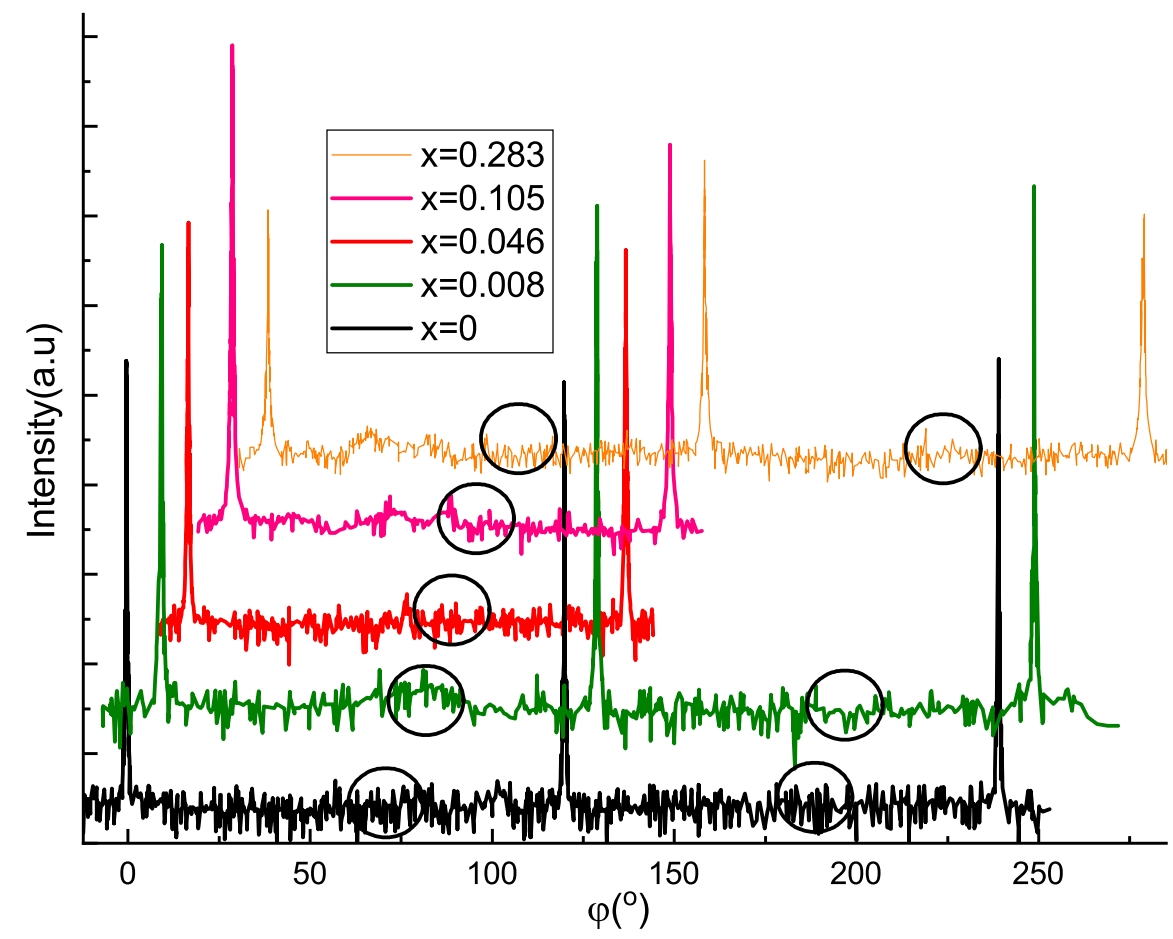

Figure 4. $\phi$ Scan of the [001] axis on (1010) reflection for films with different $x$. Circles denote angular positions of possible (not detected) twin domains. The scans are shifted along $x$ and $y$ axes for clarity.

\subsection{Transport Measurements on Thin Films}

Transport properties also show up systematic dependencies on $x$. All films have metallic type resistivity $\left(\frac{d \rho}{d T}>0\right)$ in wide range of temperatures. The value of the resistivity per square tends to enhance progressively with $\mathrm{Sr}$ doping level for all temperatures. The residual-resistance ratios (RRR), defined as ratios between the resistance at $300 \mathrm{~K}$ and minimal resistance at low $T$, are summarized in Table 1. RRR ranges from 1.4 to 2.2 for most of the $\sim 25 \mathrm{~nm}$ thick Sr-doped films. This fact indicates the similar scattering mechanisms in all samples. In some films we observe the minimum of $\rho$ and its low- $T$ upturn (see Figure $5 \mathrm{c}$ ). This minimum is believed to be caused by e-e interaction, similarly to numerous observations on undoped $\mathrm{Bi}_{2} \mathrm{Se}_{3}$ films [33].

Figure 5 collates free carrier density and mobility in the $\mathrm{Sr}$-doped $\mathrm{Bi}_{2} \mathrm{Te}_{3}$ (filled boxes) and $\mathrm{Bi}_{2} \mathrm{Se}_{3}$ films (empty boxes), respectively. As obtained from the sign of the Hall effect, all films are $n$-type. Importantly, after some drop around $x \sim 0.01$, carrier density increases with $x$ for both compounds, with more smooth behavior in telluride system, reflecting superior structural quality along with more uniform and reproducible doping process in 
Sr-doped $\mathrm{Bi}_{2} \mathrm{Te}_{3}$. Low- $x$ drop indicates that for $x$ below $\sim 0.01 \mathrm{Sr}^{2+}$ substitution for the $\mathrm{Bi}^{3+}$ works as a dominant doping mechanism, as discussed in detail in [31]. Sr atoms mostly act as scattering centers and mobility is inversely proportional to $x$.

For $x>0.02$ the doping efficiency of Sr in both materials is very small (compare $n(x)$ and dotted straight lines in Figure 8 of Reference [31]). It proves that (i) not each $\mathrm{Sr}$ atom act as a donor (moreover, the larger the value of $x$ the weaker the doping effect, and carrier density saturates); (ii) At the same time the number of scattering centers (inverse mobility, see Figure $5 b$ ) grows roughly linearly with $x$. We believe, that $\mathrm{Sr}$ atoms in the telluride lattice act at least in two ways simultaneously: in one position (substitution of Bi) they act as acceptors, whereas in the other point defect positions they may act as donors. It is also probable (see Discussion section) that Sr promotes formation of Bi-Bi bilayers, also acting as donors. Anyway the doping efficiency of $\mathrm{Sr}$ is very small. Mobility (Figure 5b) decreases with $x$ for both selenide- and telluride-based compounds.

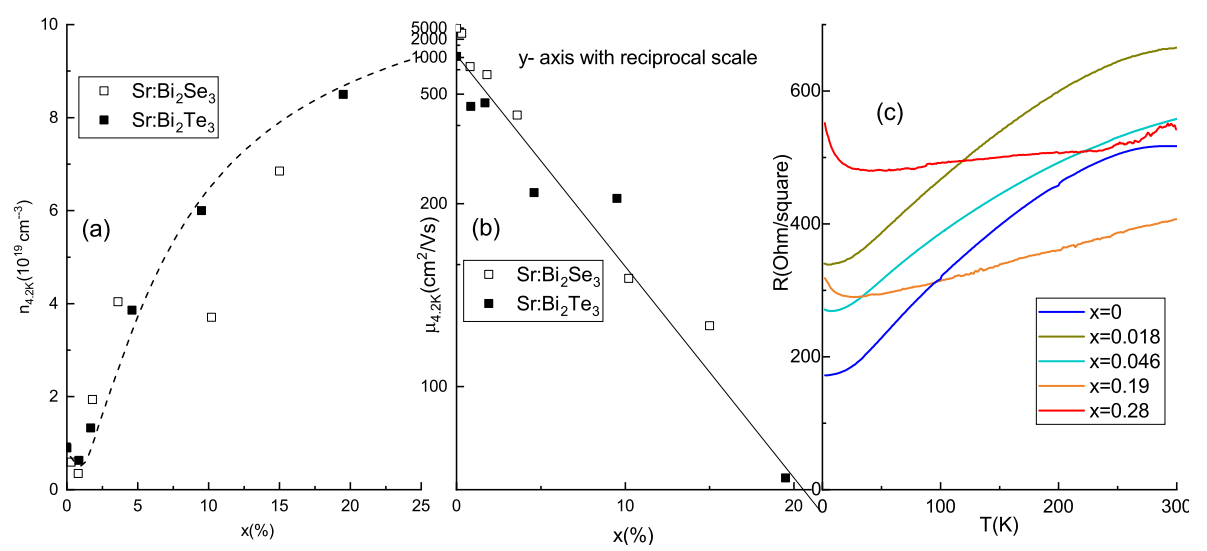

Figure 5. Transport data summary. Hall carrier density (panel (a)) and mobility (panel (b)) measured at $T=2 \mathrm{~K}$ as a function of doping level for $\sim 30 \mathrm{~nm}$ thick films $\mathrm{Bi}_{2} \mathrm{Te}_{3}$-based films (black squares). Empty squares correspond to $\mathrm{Bi}_{2} \mathrm{Se}_{3}$-based films from Reference [31] The line in panel (a) is a guide for the eye, the dashed lines in panel (b) shows approximately linear $x$-dependence interpolation of the inverse mobility. (c) Temperature dependencies of the resistivity for the representative thin films.

\section{Discussion}

In our bulk crystals promising $p$-type conductivity was obtained. However, contrary to Tl- and $\mathrm{Pd}$-doped $\mathrm{Bi}_{2} \mathrm{Te}_{3}$ [23-27], we detect no signs of superconductivity. Our melt-grown Sr-doped $\mathrm{Bi}_{2} \mathrm{Te}_{3}$ bulk single crystals contained two different minority phases: layered (trigonal or rhombohedral) $\mathrm{Bi}_{x} \mathrm{Te}_{y}$ and cubic $\mathrm{Sr}_{1-x} \mathrm{Bi}_{x} \mathrm{Te}$. So further increase of the $\mathrm{Sr}$ content is limited. Therefore we can not move the Fermi level deeply in the valence band thus increasing the density of states. We expect that variation of growth strategy and the use of different starting precursors (e.g., binary compounds instead of elements) may help to overcome this issue.

Our thin films have $n$-type of conductivity. Contrary to bulk crystals, they do not suffer from the admixture of the secondary cubic phase. In addition, Sr-doped $\mathrm{Bi}_{2} \mathrm{Te}_{3}$ films preserve high structural perfection at least to $x \sim 0.2$, when the carrier density reaches about $10^{20} \mathrm{~cm}^{-3}$, i.e., density typical for superconducting doped $n$-type $\mathrm{Bi}_{2} \mathrm{Se}_{3}$ materials. However this film are not superconductive. A precise knowledge of the Sr atoms location would be helpful to understand the key structural factor responsible for superconductivity in doped TI.

An ordered stacking of Te1-Bi-Te2-Bi-Te1 quintuple layers (QLs) and Bi-Bi bilayers (Bi BLs) building blocks may form bulk crystals of the $\left(\mathrm{Bi}_{2}\right)_{m}\left(\mathrm{Bi}_{2} \mathrm{Te}_{3}\right)_{n}$ adaptive series [39]. In binary $\mathrm{Bi}_{2} \mathrm{Te}_{3}$ layers grown by $\mathrm{MBE}$, excess BLs randomly inserted between the QLs were also observed [34,40,41]. Depending on the Te deficient flux and other growth conditions, and despite a statistical distribution of the additional Bi BLs, various phases such as $\mathrm{Bi}_{4} \mathrm{Te}_{5}$ [40], $\mathrm{Bi}_{4} \mathrm{Te}_{3}$ [41] and $\mathrm{Bi}_{1} \mathrm{Te}_{1}$ [34] were identified in thin epitaxial films. More 
interestingly, MBE grown Mn-doped bismuth telluride thin films reveal the crystalline phase in which several $\mathrm{Bi}_{2} \mathrm{Te}_{3}$ quintuple layers were separated by Bi BLs [42].

Under adopted growth conditions in this paper, stoichiometric $\mathrm{Bi}_{2} \mathrm{Te}_{3}$ epi-layers are obtained with no signs of Bi-BLs, as evidenced by angular position of narrow diffraction peaks and supported by a rather high carrier mobility for sample with $x=0$. As compared with Eu-doped $\mathrm{Bi}_{2} \mathrm{Te}_{3}$ [43] or Sr-doped $\mathrm{Bi}_{2} \mathrm{Se}_{3}$ films [31], our $\mathrm{Sr}_{x} \mathrm{Bi}_{2} \mathrm{Te}_{3}$ layers do not suffer from progressing structural disorder with doping level. On the contrary, as evidenced from (0 06 ) reflection thickness fringes (Figure $2 b$ ), moderate broadening of diffraction peaks (see Figure 2a along with column $\Delta \omega_{(0015)}$ of Table 1) and free carrier mobility (Figure $5 b$ ) in $\mathrm{Sr}_{x} \mathrm{Bi}_{2-x} \mathrm{Te}_{3}$ layers high crystallinity is preserved for $x$ up to 0.2. These facts along with composition insensitive in-plane lattice parameter $a$ allow us to assume that $\mathrm{Sr}$ incorporation in $\mathrm{Bi}_{2} \mathrm{Te}_{3}$ matrix favours Bi BLs to form between two consecutive $\mathrm{Bi}_{2} \mathrm{Te}_{3}$ QLs inside the van der Waals gap. Moreover, Sr dopant atoms are predominantly incorporated in this distributed Bi-Bi network. Sr as a one of the most active chemical element in the periodic Table may easily bind Te atoms and provoke Te-deficient growth conditions. Even as small deviation from stoihiometry as $-0.02\left(\mathrm{Bi}_{2} \mathrm{Te}_{2.98}\right)$ may produce $10 \%$ of Bi BLs in the film [44]. When increasing Sr content, the structure should change from pure $\mathrm{Bi}_{2} \mathrm{Te}_{3}$ phase through intermediate $\mathrm{Bi}_{x} \mathrm{Te}_{y}$ towards the $\mathrm{Bi}_{1} \mathrm{Te}_{1}$ phase, in which Bi-Bi BLs occurs periodically after each pair of QLs Te-Bi-Te-Bi-Te.

As it was previously demonstrated, XRD analysis is capable of detecting Bi interlayers in bismuth telluride matrix $[45,46]$. However, symmetrical (0 03l) XRD reflections can not reveal single layer of the phases $\mathrm{BiTe}_{\mathrm{T}} \mathrm{Bi}_{3} \mathrm{Te}_{4}$ with the period $24 \AA$ and $41.5 \AA$, respectively, due to broadened signal. It is necessary therefore to use a grazing diffraction in order to maximally elongate the path of the beam through the thin film. (101) reflection of $\mathrm{Bi}_{2} \mathrm{Te}_{3}$ is the most siutable for this purpose, because the sample plane has an angle $\psi=82.9^{\circ}$ with respect to the normal orientation, that corresponds to $\sim 8$ times path elongation. Reflections (101) for the BiTe and $\mathrm{Bi}_{3} \mathrm{Te}_{4}$ phases will be located near the $\mathrm{Bi}_{2} \mathrm{Te}_{3}$ one. These reflections have maximal intensity for slightly different values of $\psi$ (see Table 2), that allows systematic search of these phases.

Table 2. Lattice constants and parameters of the relevant closely-placed asymmetrical reflection used to detect admixture of Bi BL-mediated phases. $\psi$ is indicated with respect to $(001)$-direction.

\begin{tabular}{ccccc}
\hline Composition & $c(\AA)$ & $\boldsymbol{a}(\AA)$ & $\boldsymbol{\theta}\left({ }^{\circ}\right)$ & $\psi\left({ }^{\circ}\right)$ \\
\hline $\mathrm{Bi}_{2} \mathrm{Te}_{3}$ & 30.6065 & 4.3835 & 11.799 & 82.93 \\
$\mathrm{BiTe}$ & 24.002 & 4.402 & 11.806 & 80.98 \\
$\mathrm{Bi}_{3} \mathrm{Te}_{4}$ & 41.50 & 4.416 & 11.670 & 84.73 \\
\hline
\end{tabular}

Rocking curves recorded at the (101) peak at $\psi=82.9^{\circ}$ for three samples with increasing Sr content are shown in Figure 6. Vertical arrows indicate peaks corresponding to secondary phases. Sample with $x=0.018$ demonstrates a pure $\mathrm{Bi}_{2} \mathrm{Te}_{3}$ phase yet. When Sr composition is increased to $x=0.195$ the structure transforms into $\left(\mathrm{Bi}_{2} \mathrm{Te}_{3}+\mathrm{Bi}_{3} \mathrm{Te}_{4}\right)$ phase admixture. Further, with $x=0.293 \mathrm{Bi}_{2} \mathrm{Te}_{3}$ matrix is converted to $\mathrm{Bi}_{2} \mathrm{Te}_{3}+\mathrm{BiTe}$. So, we clearly demonstrated the presence and increase of Bi BL content with Sr composition in our thin films. The positions of the peaks for both $\mathrm{BiTe}_{\mathrm{T}}$ and $\mathrm{Bi}_{3} \mathrm{Te}_{4}$ are shifted with respect to the estimated values. This is due to higher thermal expansion coefficients $\mathrm{BaF}_{2}$ substrate with respect to a film. After the growth therefore the film is contracted in the basal plane when cooled down to room temperature. This effect was not taken into account in Table 2, where room temperature lattice parameters are given for single-crystalline phases. 


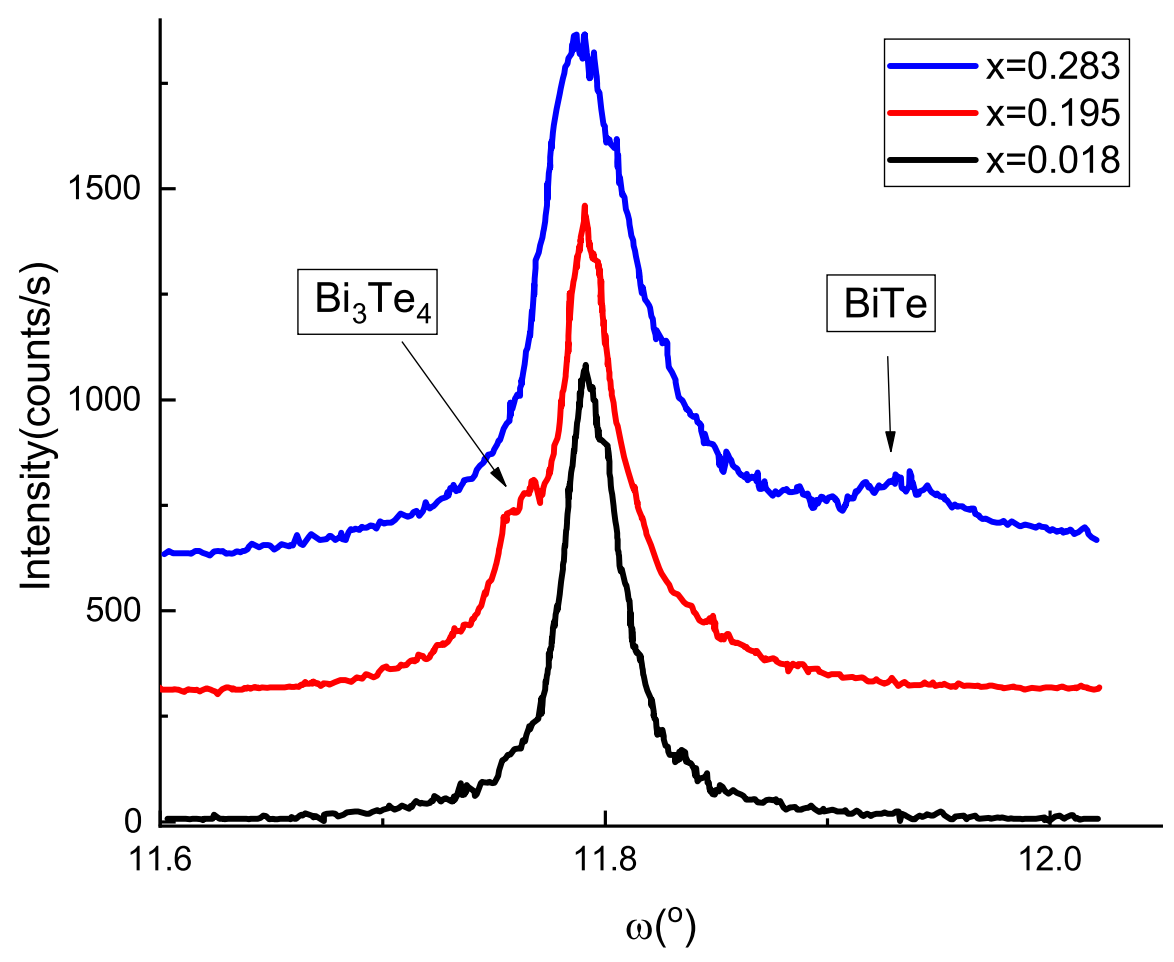

Figure 6. Rocking curves at (101) reflections for three different compositions demonstrating formation of Bi bilayers in the structure of the films.

It was demonstrated previously [45] that Bi BLs in $\mathrm{Bi}_{2} \mathrm{Te}_{3}$ films act as electron donors, producing electron concentration well above $10^{20} \mathrm{~cm}^{-3}$. At the same time mobility was found to drop 50 times (down to $30 \mathrm{~cm}^{2} \mathrm{~V}^{-1} \mathrm{~s}^{-1}$ ) due to the asynchronous incorporation of the Bi doublets across the surface during growth. So, detected Bi BLs (Figure 6) could explain transport and structural features observed in our films.

\section{Conclusions}

In our paper, we report an effort to get superconducting Sr-doped $\mathrm{Bi}_{2} \mathrm{Te}_{3}$ bulk crystals and epitaxial thin films. While Bridgman grown $\mathrm{Sr}_{x} \mathrm{Bi}_{2} \mathrm{Te}_{3}$ single crystals have $p$-type conductivity, the parent compound films demonstrate $n$-type transport. None of the studied samples demonstrated superconductivity down to $1.6 \mathrm{~K}$. In thin films $\mathrm{Sr}$ atoms induce formation of Bi BLs and predominantly are located within arranged Bi-Bi network. We believe, that information on exact location of Sr dopants is the key factor to resolve the problem and achieve superconducting phase. At present time even in superconducting selenides $\mathrm{M}_{x} \mathrm{Bi}_{2} \mathrm{Se}_{3}$ (where $\mathrm{M}=\mathrm{Sr}, \mathrm{Cu}, \mathrm{Nb}$ ) matrix crystallographic dopant positions are not reliably established [47]. Our results should be helpful for the control of $\mathrm{Bi}_{2} \mathrm{Te}_{3}$ properties by doping and indicate that further studies of doped TI are needed to create novel topological superconductors.

Author Contributions: Conceptualization, Y.G.S. and A.Y.K.; sample growth, Y.G.S.; data analysis, Y.G.S.; measurements, V.P.M. (X-ray diffraction) and M.I.B. (transport measurements); writingoriginal draft preparation, Y.G.S.; writing—review and editing, A.Y.K.; visualization, A.Y.K.; project administration, A.Y.K. All authors have read and agreed to the published version of the manuscript.

Funding: The work was supported by Russian Science Foundation (Grant N 17-12-01544).

Institutional Review Board Statement: Not applicable.

Informed Consent Statement: Not applicable.

Data Availability Statement: The data presented in this study are available in the article. On request the data in raw format could be requested from the corresponding authors. 
Acknowledgments: Magnetotransport and XRD measurements were performed using the equipment of the LPI shared facility center.

Conflicts of Interest: The authors declare no conflict of interest. The funders had no role in the design of the study; in the collection, analyses, or interpretation of data; in the writing of the manuscript, or in the decision to publish the results.

\section{Abbreviations}

The following abbreviations are used in this manuscript:

$\begin{array}{ll}\text { XRD } & \text { X-ray diffraction } \\ \text { XRR } & \text { X-ray reflection } \\ \text { MBE } & \text { Molecular beam epitaxy } \\ \text { TSC } & \text { Topological superconductivity } \\ \text { 3D } & \text { Three-dimensional } \\ \text { TI } & \text { Topological insulator } \\ \text { BEP } & \text { beam equivalent pressure } \\ \text { CFMS } & \text { Cryomagnetic measurement system } \\ \text { BL } & \text { bilayer } \\ \text { QL } & \text { quintuple layer }\end{array}$

\section{Appendix A. XRD Determination of Admixture Phases and Lattice Parameters in Single Crystals}

We selected a piece of 347 sample and performed $2 \theta$ scan (see Figure A1a). There are three additional peaks (marked by the arrows). Two of them at $2 \theta=37.69^{\circ}$ and $2 \theta=65.95^{\circ}$ could be interpreted either as BiTe (0010) and (0 0 17) reflections or as (220) and (420) of the cubic phase $\operatorname{SrTe}(a=6.47 \AA)$ with sligtly reduced value of the lattice parameter (6.30-6.33 $\AA$ ). At the same time the peak at $2 \theta=28.03^{\circ}$ corresponds to the strongest $(200)$ reflection of SrTe with lattice parameter $a=6.36 \AA$. This peak is absent in BiTe and $\mathrm{Bi}_{3} \mathrm{Te}_{4}$ phases. Our data are thus indicative for the inclusions of the second phase $\mathrm{Sr}_{1-x} \mathrm{Bi}_{x} \mathrm{Te}$ with small value of $x$ that modifies the lattice constant.

$c$-lattice parameter in tetradymite structure materials can be straightforwardly determined from the $2 \theta / \omega$ scans at intensive symmetrical reflections (either (0 06$)$ or $(0015)$, see examples in Figures 1 and 2 and Table 1).

For these precise measurements a triple $\mathrm{Ge}(220) \times 3$ crystal-monochromator was used that provided 12" angular resolution. Prior to measurements zero position of the diffractometer was set using (004) reflection of the ultra pure silicon crystal with the well known lattice parameter $a_{S i}=5.43105 \AA$. In order to determine the in-plane lattice parameter $a$ a grazing diffraction geometry was used at (205) reflections with inclination angle $\psi=72.5^{\circ}$. These reflections are three-fold repeated and should be reproduced as the sample is rotated by $\Delta \phi=120^{\circ}$ about the axis, perpendicular to basal plane. 

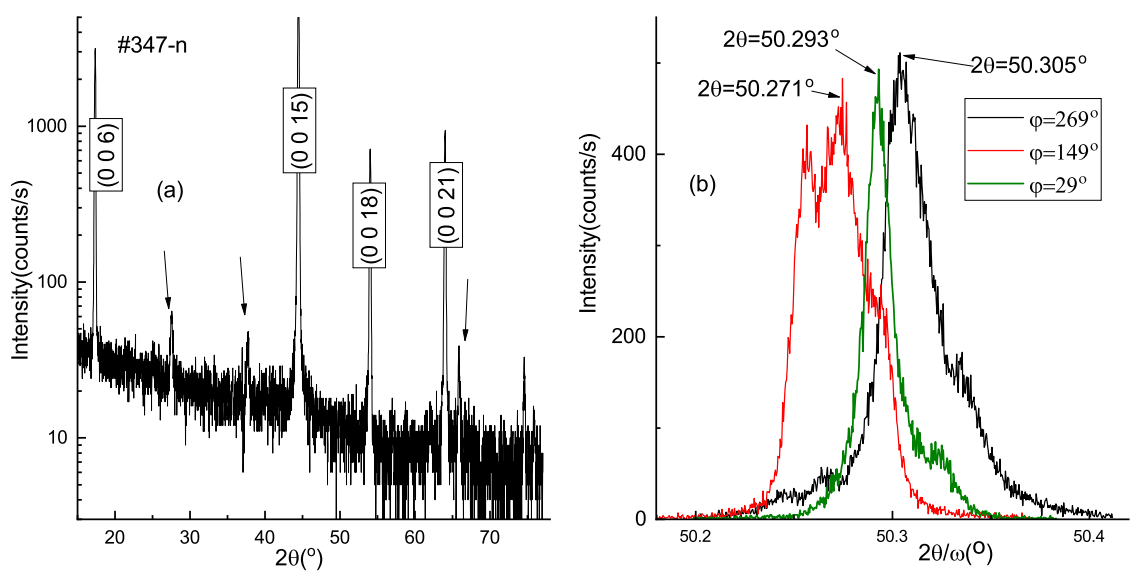

Figure A1. High resolution XRD data for sample 347. (a) $2 \theta$ scan of the selected piece of the crystal. The arrows indicate the peaks demonstrating the presence of the cubic phase. (b) $2 \theta / \omega$ scans at the asymmetric (205) reflection collected for three polar angles (indicated in the panel).

Angular position of these reflections in $2 \theta / \omega$ scans together with previously measured $c$-lattice parameter allows to determine $a$-parameter. Figure A1b shows $2 \theta / \omega$-scans collected for the same sample (347) in three different directions. The values of $a$-parameter calculated with known $c=30.493 \AA$ range from $4.3835 \AA$ to $4.3865 \AA$. In other words this crystal has in-plane structural distortions.

\section{References}

1. Heremans, J.P.; Cava, R.J.; Samarth, N. Tetradymites as thermoelectrics and topological insulators. Nat. Rev. Mater. 2017, 2, 17049. [CrossRef]

2. Tokura, Y.; Yasuda, K.; Tsukazaki, A. Magnetic topological insulators. Nat. Rev. Phys. 2019, 1, 126-143. [CrossRef]

3. Yonezawa, S. Nematic Superconductivity in Doped $\mathrm{Bi}_{2} \mathrm{Se}_{3}$ Topological Superconductors. Condens. Matted 2019, 4, 2. [CrossRef]

4. Zhang, H.; Zhang, X.; Liu, C.; Lee, S.-T.; Jie, J. High-Responsivity, High-Detectivity, Ultrafast Topological Insulator $\mathrm{Bi}_{2} \mathrm{Se}_{3} / \mathrm{Silicon}$ Heterostructure Broadband Photodetectors. ACS Nano 2016, 10, 5113. [CrossRef] [PubMed]

5. Koo, J.; Ashok, N.; Kim, D.H.; Shin, W. Bi $2 \mathrm{Te}_{3}$ Topological Insulator for Domain-Wall Dark Pulse Generation from Thulium-Doped Fiber Laser. Crystals 2019, 9, 337. [CrossRef]

6. Elliott, S.R.; Franz, M. Colloquium: Majorana fermions in nuclear, particle, and solid-state physics. Reviwws Mod. Phys. 2015, 87, 137. [CrossRef]

7. Fu, L.; Kane, C.L. Superconducting Proximity Effect and Majorana Fermions at the Surface of a Topological Insulator. Phys. Rev. Lett. 2008, 100, 096407. [CrossRef] [PubMed]

8. Das Sarma, S.; Freedman, M.; Nayak, C. Majorana zero modes and topological quantum computation. Npj Quantum Inf. 2015, 1, 15001. [CrossRef]

9. Sato, M.; Ando,Y. Topological superconductors: A review. Rep. Prog. Phys. 2017, 80, 076501. [CrossRef] [PubMed]

10. Sasaki, S.; Kriener, M.; Segawa, K.; Yada, K.; Tanaka, Y.; Sato, M.; Ando, Y. Topological Superconductivity in $\mathrm{Cu}_{x} \mathrm{Bi}_{2} \mathrm{Se}_{3}$. Phys. Rev. Lett. 2011, 107, 217001. [CrossRef] [PubMed]

11. Tao, R.; Yan, Y.-J.; Liu, X.; Wang, X.; Ando, Y.; Wang, Q.-H.; Zhang, Q.-H.; Feng, D.-L. Direct Visualization of the Nematic Superconductivity in $\mathrm{Cu}_{x} \mathrm{Bi}_{2} \mathrm{Se}_{3}$. Phys. Rev. 2018, 8, 041024. [CrossRef]

12. Qi, X.-L.; Zhang, S.-C. Topological insulators and superconductors. Rev. Mod. Phys. 2011, 83, 1057. [CrossRef]

13. Kirshenbaum, K.; Syers, P.S.; Hope, A.P.; Butch, N.P.; Jeffries, J.R.; Weir, S.T.; Hamlin, J.J.; Maple, M.B.; Vohra, Y.K.; Paglione, J. Pressure-Induced Unconventional Superconducting Phase in the Topological Insulator $\mathrm{Bi}_{2} \mathrm{Se}_{3}$. Phys. Rev. Lett. 2013, 111, 087001. [CrossRef] [PubMed]

14. Zhang, J.L.; Zhang, S.J.; Weng, H.M.; Zhang, W.; Yang, L.X.; Liu, Q.Q.; Feng, S.M.; Wang, X.C.; Yu, R.C.; Cao, L.Z.; et al. Pressure-induced Superconductivity in Topological Parent Compound $\mathrm{Bi}_{2} \mathrm{Te}_{3}$. Proc. Natl. Acad. Sci. USA 2011, 108, 24. [CrossRef]

15. Li, Y.; Xu, Z.-A. Exploring Topological Superconductivity in Topological Materials. Adv. Quantum Technol. 2019, 2, 1800112. [CrossRef]

16. Hor, Y.S.; Williams, A.J.; Checkelsky, J.G.; Roushan, P.; Seo, J.; Xu, Q.; Zandbergen, H.W.; Yazdani, A.; Ong, N.P.; Cava, R.J. Superconductivity in $\mathrm{Cu}_{x} \mathrm{Bi}_{2} \mathrm{Se}_{3}$ and its Implications for Pairing in the Undoped Topological Insulator. Phys. Rev. Lett. 2010, 104, 057001. [CrossRef]

17. Liu, Z.; Yao, X.; Shao, J.; Zuo, M.; Pi, L.; Tan, S.; Zhang, C.; Zhang, Y. Superconductivity with topological surface state in $\mathrm{Sr}_{x} \mathrm{Bi}_{2} \mathrm{Se}$ J. Am. Chem. Soc. 2015, 137, 10512-10515. [CrossRef] [PubMed] 
18. Pan, Y.; Nikitin, A.M.; Araizi, G.K.; Huang, Y.K.; Matsushita, Y.; Naka, T.; de Visser, A. Rotational symmetry breaking in the topological superconductor $\mathrm{Sr}_{x} \mathrm{Bi}_{2} \mathrm{Se}_{3}$ probed by upper-critical field experiments. Sci. Rep. 2016, 6, 28632. [CrossRef]

19. Kuntsevich, A.Y.; Bryzgalov, M.A.; Prudkoglyad, V.A.; Martovitskii, V.P.; Selivanov, Y.G.; Chizhevskii, E.G. Structural distortion behind the nematic superconductivity in $\mathrm{Sr}_{x} \mathrm{Bi}_{2} \mathrm{Se}_{3}$. New J. Phys. 2018, 20, 103022. [CrossRef]

20. Kuntsevich, A.Y.; Bryzgalov, M.A.; Akzyanov, R.S.; Martovitskii, V.P.; Rakhmanov, A.L.; Selivanov, Y.G. Strain-driven nematicity of odd-parity superconductivity in $\mathrm{Sr}_{x} \mathrm{Bi}_{2} \mathrm{Se}_{3}$. Phys. Rev. B 2019, 101, 224509. [CrossRef]

21. Almoalem, A.; Silber, I.; Sandik, S.; Lotem, M.; Ribak, A.; Nitzav, Y.; Kuntsevich, A.Y.; Sobolevskiy, O.A.; Selivanov, Y.G.; Prudkoglyad, V.A. Link between superconductivity and a Lifshitz transition in intercalated $\mathrm{Bi}_{2} \mathrm{Se}_{3}$. Phys. Rev. B 2021, $103,174518$. [CrossRef]

22. Asaba, T.; Lawson, B.J.; Tinsman, C.; Chen, L.; Corbae, P.; Li, G.; Qiu, Y.; Hor, Y.S.; Fu, L.; Li, L. Rotational Symmetry Breaking in a Trigonal Superconductor $\mathrm{Nb}$-doped $\mathrm{Bi}_{2} \mathrm{Se}_{3}$. Phys. Rev. X 2017, 7, 011009. [CrossRef]

23. Hor, Y.S.; Checkelsky, Y.S.; Qu, D.; Ong, N.P.; Cava, R.J. Superconductivity and non-metallicity induced by doping the topological insulators $\mathrm{Bi}_{2} \mathrm{Se}_{3}$ and $\mathrm{Bi}_{2} \mathrm{Te}_{3}$. J. Phys. Chem. Solids 2011, 72, 572-576. [CrossRef]

24. Trang, C.X.; Wang, Z.; Takane, D.; Nakayama, K.; Souma, S.; Sato, T.; Takahashi, T.; Taskin, A.A.; Ando, Y. Fermiology of possible topological superconductor $\mathrm{Tl}_{0.5} \mathrm{Bi}_{2} \mathrm{Te}_{3}$ derived from hole-doped topological insulator. Phys. Rev. B 2016, 93, 241103. [CrossRef]

25. Singh, Y. The $H-T$ and $P-T$ Phase Diagram of the Superconducting Phase in Pd:Bi $\mathrm{T}_{3}$. J. Supercondunc. Nov. Magn. 2016, 29, 1975.

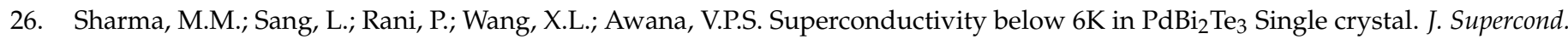
Nov. Magn. 2020, 33, 1243. [CrossRef]

27. Wang, Z.; Taskin, A.A.; Frölich, T.; Braden, M.; Ando, Y. Superconductivity in $\mathrm{Tl}_{0.6} \mathrm{Bi}_{2} \mathrm{Te}_{3}$ Derived from a Topological Insulator. Chem. Mater. 2016, 28, 779. [CrossRef]

28. He, L.Q.; Liu, H.; He, M.; Lai, Y.H.; He, H.; Wang, G.; Law, K.T.; Lortz, R.; Wang, J.; Sou, I.K. Two-dimensional superconductivity at the interface of $\mathrm{a} \mathrm{Bi}_{2} \mathrm{Te}_{3} / \mathrm{FeTe}$ heterostructure. Nat. Commun. 2014, 5, 4247. [CrossRef]

29. Yasuda, K.; Yasuda, H.; Liang, T.; Yoshimi, R.; Tsukazaki, A.; Takahashi, K.S.; Nagaosa, N.; Kawasaki, M.; Tokura, Y. Nonreciprocal charge transport at topological insulator/superconductor interface. Nat. Commmun. 2019, 10, 2734. [CrossRef] [PubMed]

30. Qin, H.; Guo, B.; Wang, L.; Zhang, M.; Xu, B.; Shi, K.; Pan, T.; Zhou, L.; Chen, J.; Qiu, Y.; et al. Superconductivity in SingleQuintuple-Layer $\mathrm{Bi}_{2} \mathrm{Te}_{3}$ Grown on Epitaxial FeTe. Nano Lett. 2020, 20, 3160. [CrossRef]

31. Volosheniuk, S.O.; Selivanov, Y.G.; Bryzgalov, M.A.; Martovitskii, V.P.; Kuntsevich, A.Y. Effect of Sr doping on structure, morphology, and transport properties of $\mathrm{Bi}_{2} \mathrm{Se}_{3}$ epitaxial thin films. J. Appl. Phys. 2019, 125, 095103. [CrossRef]

32. Schneeloch, J.A.; Zhong, R.D.; Xu, Z.J.; Gu, G.D.; Tranquada, J.M. Dependence of superconductivity in $\mathrm{Cu}_{x} \mathrm{Bi}_{2} \mathrm{Se}_{3}$ on quenching conditions. Phys. Rev. B 2015, 91, 144506. [CrossRef]

33. Kuntsevich, A.Y.; Gabdullin, A.A.; Prudkogliad, V.A.; Selivanov, Y.G.; Chizhevskii, E.G.; Pudalov, V.M. Low-temperature Hall effect in bismuth chalcogenides thin films. Phys. Rev. B 2016, 94, 235401. [CrossRef]

34. Caha, O.; Dubroka, A.; Humlicek, J.; Holy, V.; Steiner, H.; Ul-Hassan, M.; Sanchez-Barriga, J.; Rader, O.; Stanislavchuk, T.N.; Sirenko, A.A.; et al. Growth, structure, and electronic properties of epitaxial bismuth telluride topological insulator films on $\mathrm{BaF}_{2}$ (111) substrates. Cryst. Growth Des. 2013, 13, 3365. [CrossRef]

35. Kuntsevich, A.Y.; Martovitskii, V.P.; Rybalchenko, G.V.; Selivanov, Y.G.; Bannikov, M.I.; Sobolevskiy, O.A.; Chigevskii, E.G. Superconductivity in $\mathrm{Cu}$ co-doped $\mathrm{Sr}_{x} \mathrm{Bi}_{2} \mathrm{Se}_{3}$ single crystals. Materials 2019, 12, 3899. [CrossRef]

36. Martovitskii, V.P.; Selivanov, Y.G.; Kuntsevich, A.Y. Vicinal Growth as a Possible Structural Source of the Nematic Superconductivity in $\mathrm{Sr}_{x} \mathrm{Bi}_{2} \mathrm{Se}_{3}$. Bull. Lebedev Phys. Inst. 2020, 47, 119-122. [CrossRef]

37. Fewster, P.F. X-ray Scattering from Semiconductors; Imperial College Press: London, UK, 2003.

38. Kamenskyi, D.L.; Pronin, A.V.; Benia, H.M.; Martovitskii, V.P.; Pervakov, K.S.; Selivanov, Y.G. Bulk Cyclotron Resonance in the Topological Insulator $\mathrm{Bi}_{2} \mathrm{Te}_{3}$. Crystals 2020, 10, 722. [CrossRef]

39. Bos, J.W.G.; Zandbergen, H.W.; Lee, M.-H.; Ong, N.P.; Cava, R.J. Structures and thermoelectric properties of the infinitely adaptive series $\left(\mathrm{Bi}_{2}\right)_{m}\left(\mathrm{Bi}_{2} \mathrm{Te}_{3}\right)_{n}$. Phys. Rev. B 2007, 75, 195203. [CrossRef]

40. Fornari, C.I.; Rappl, P.H.O.; Morelhão, S.L.; Abramof, E. Structural properties of $\mathrm{Bi}_{2} \mathrm{Te}_{3}$ topological insulator thin films grown by molecular beam epitaxy on (111) $\mathrm{BaF}_{2}$ substrates. J. Appl. Phys. 2016, 119, 165303. [CrossRef]

41. Fulop, A.; Song, A.; Charpentier, S.; Shi, P.; Ekström, M.; Galletti, L.; Arpaia, R.; Bauch, T.; Lombardi, F.; Wang, S. Phase transition of bismuth telluride thin films grown by MBE. Appl. Phys. Express 2014, 7, 045503. [CrossRef]

42. Lee, J.S.; Richardella, A.; Rench, D.W.; Fraleigh, R.D.; Flanagan, T.C.; Borchers, J.A.; Tao, J.; Samarth, N. Ferromagnetism and spin-dependent transport in n-type Mn-doped bismuth telluride thin films. Phys. Rev. B 2014, 89, 174425. [CrossRef]

43. Balin, K.; Wojtyniak, M.; Weis, M.; Zubko, M.; Wilk, B.; Gu, R.; Ruello, P.; Szade, J. Europium Doping Impact on the Properties of MBE Grown $\mathrm{Bi}_{2} \mathrm{Te}_{3}$ Thin Film. Materials 2020, 13, 3111. [CrossRef]

44. Kagerer, P.; Fornari, C.I.; Buchberger, S.; Morelhão, S.L.; Vidal, R.C.; Tcakaev, A.; Zabolotnyy, V.; Weschke, E.; Hinkov, V.; Kamp, M.; et al. Molecular beam epitaxy of antiferromagnetic $\left(\mathrm{MnBi}_{2} \mathrm{Te}_{4}\right)\left(\mathrm{Bi}_{2} \mathrm{Te}_{3}\right)$ thin films on $\mathrm{BaF}_{2}$ (111). J. Appl. Phys. 2020, $128,135303$. [CrossRef]

45. Steiner, H.; Volobuev, V.; Caha, O.; Bauer, G.; Springholz G.; Holỳ, V. Structure and composition of bismuth telluride topological insulators grown by molecular beam epitaxy. J. Appl. Cryst. 2014, 47, 1889-1900. [CrossRef] 
46. Kriegner, D.; Harcuba, P.; Veselý, J.; Lesnik, A.; Bauer, G.; Springholz, G.; Holỳ, V. Twin domain imaging in topological insulator $\mathrm{Bi}_{2} \mathrm{Te}_{3}$ and $\mathrm{Bi}_{2} \mathrm{Se}_{3}$ epitaxial thin films by scanning X-ray nanobeam microscopy and electron backscatter diffraction. J. Appl. Cryst. 2017, 50, 369-377. [CrossRef]

47. Lin, Y.-R.; Bagchi, M.; Soubatch, S.; Lee, T.-L.; Brede, J.; Bocquet, F.C.; Kumpf, C.; Ando, Y.; Tautz, F.S. Vertical Position of Sr Dopants in the $\mathrm{Sr}_{x} \mathrm{Bi}_{2} \mathrm{Se}_{3}$. Phys. Rev. B 2021, 104, 054506. [CrossRef] 